\title{
Da presença de formas de evolução do Trypanosoma cruzi Chagas, nos tubos de Malpighi do barbeiro (*)
}

\author{
(Nota prévia)
}

\author{
por \\ EMMANUEL DIAS \\ (Com as estampas LVIII-LX).
}

Tivemos excellente opportunidade para retomar o estudo do cyclo do Trypanosoma cruzi no invertebrado transmissor, graças á bôa vontade e poderoso estimulo do Professor Carlos Chagas.

Desde o inicio de nossos trabalhos servima-nos sempre do principal vector natural da doença de Chagas, o Triatoma megista, nas diversas phases de sua evolução. Para a dissecção do insecto, com o fim de isolar o tubo digestivo e orgãos abdominaes annexos, procedemos da seguinte maneira: separadas as pernas e as azas, e aberto o corpo pela face dorsal, tiramos os musculos thoraxicos e os orgãos genitaes e, depois de desfazer as adherencias dos orgãos restantes com a face ventral, mergulhamos o todo no liquido fixador; a dissecção é terminada quando os tecidos tenham adquirido rigidez e consistencia bastantes para que as differentes partes conservem o melhor possivel suas fórmas e relações. Os fixadores mais usados foram o sublimado alcool de (Schaudinn modificado por Mayer e, preferentemente, o liquido de Carnoy). Após inclusãa em parafina eram praticados córtes seriados ( 5 e 6 micra) e corados pelo Giemsa e pela hemaloxylina ferrica. Além desta technica, servimo-nos secundariamente de esfregaços fixados a humido, corados pelos mesmos methodos, e de exames a fresco. Pudemos, por estes meios, examinar algumas dezenas de triatomas, em sua maioria provenientes de regióes onde existe trypanosomiase endemica e naturalmente infectados, e alguns criados e infectados no laboratorio. 
No estomago e no intestino posterior verificámos quasi todas as fórmas já descriptas (Chagas, Brumpt, Mayer e Rocha Lima, Gomes de Faria e O. Cruz Filho). Além das differentes fórmas cyclicas encontradas. no conducto digestivo, observámos, em alguns hemipteros adultos, no interior dos tubos de Malpighi, parasitos sob a fórma de crithidias, ás vezes ahi accumuladas em grande numero. A extensão que occupam dos referidos tubos é bastante variavel, ora nelles se introduzindo até longe do tubo intestinal, ora limitando-se ás proximidades deste. As regiões do apparelho excretor mais constantemente infectadas são as empolas terminaes dos tubos de Malpighi. Estas empolas existem em numero dia quatro no barbeiro, e abrem-se no intestino ao nivel do pyloro dando origem ahi a uma formação epithelial (constituida por cellulas baixas derivadas de seu proprio epithelio) que provavelmente têm a funcção de valvula. E' muito frequente a presença de crithidias nesta porção do apparelho excretor e sua disposição muito constante. Mantêm-se a maioria das vezes perpendicularmente á superficie das cellulas epitheliaes, ás quaes conservam-se presas por sua extremidade anterior. Por vezes o numero de flagellados é enorme, mostrando-se cerradamente dispostos lado a lado e occupando quasi toda a superficie interna da empôla. A localisação de trypanosomidas de outros generos nos tubos de Malpighi de insectos é bem conhecida; assim, a Leptomonas ctenocephali (Fantham, 1912) invade commumente os tubos excretores da pulga do cão (Ctenocephalus canis), do mesmo modo que os da pulga do homem, Pulex irritans (Leptomonas pulicis, Paton e Rao 1921, syn.). Em diversas especies de drosophilas parasitadas por flagellados os tubos de Malpighi são invadidos occasional ou obrigatoriamente, como p. ex. pela Herpetomonas roubaudi (Leptomonas r., Chaton 1912).

Fóra dos limites anatomicos do apparelho malpighiano, em pleno intestino posterior, ás fórmas evolutivas do $T$. cruzi conservam-se ainda adherentes e perpendiculares á superficie epithelial, sob aspectos morphologicos differentes. Esta disposição intestinal, commum em muitos trypanosomidas, embora ainda não tenha sido descripta, foi anteriormente observada por J. Gomes de Faria e O. Cruz Filho e, de accôrdo com suá interpretação, as fórmas ahi encontradas são analogas ás descriptas por Minchin e Thomson na "phase rectal» do T. lewisi (Quart. Jour. of Micr. Science, 1915).

Não nos é possivel ainda, como fôra de desejar, estabelecer o cyclo completo do $T$. cruzi, nelle determinando o logar occupado pelas fórmas encontradas no apparelho excretor; entretanto não parece precipitado admittir que as referidas fórmas representem phase de activa mul- 
tipicação do protozoario, com accentuado tropismo por essas regiões. De accôrdo com a interpretação logica e natural de Chagas, o parasito ahi encontraria condições mais propicias ao seu desenvolvimento, subtrahido á concorrencia vital da abundante flóra bacteriana intestinal.

\section{EXPLICAÇÃO DAS ESTAMPAS LVIII-LX}

\section{ESTAMPA LVIII}

Tubos de Malpighi, cortados em diversos sentidos, contendo numerosos flagellados. Fix. Carnoy. Col. Giemsa ( $\times$ ca. 530).

\section{ESTAMPAS LIX-LX}

Numerosas crithidias dispostas com regularidade e perpendicularmente ás cellulas epitheliaes das empolas terminaes do tubo de Malpighi, vistas sob differentes augmentos. Fix. Mayer. Col. Heidenhain $(\times 507$ e $\times 208)$. 


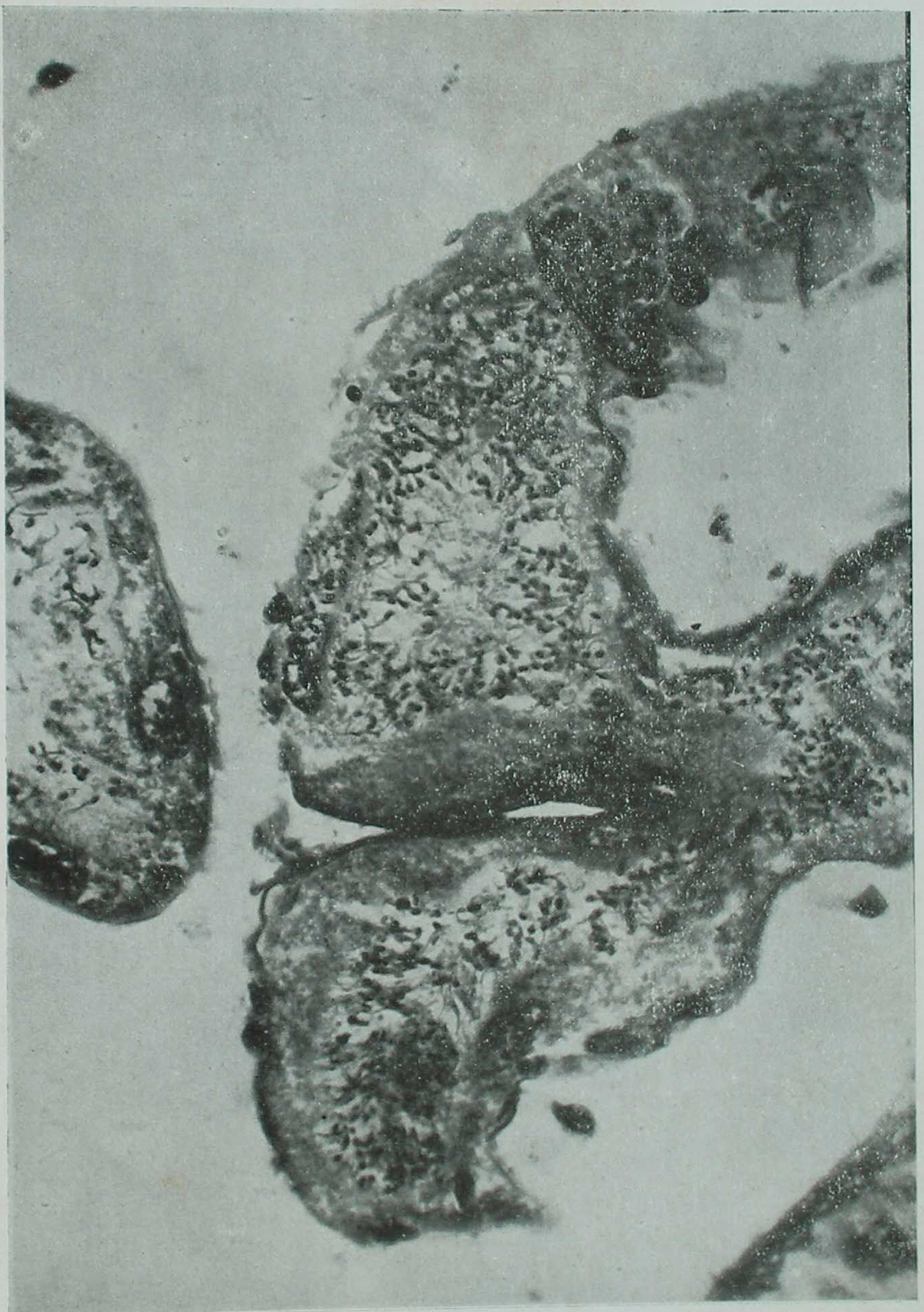

Emmanuel Dias : Formas de evolução do $T$. cruzi. 


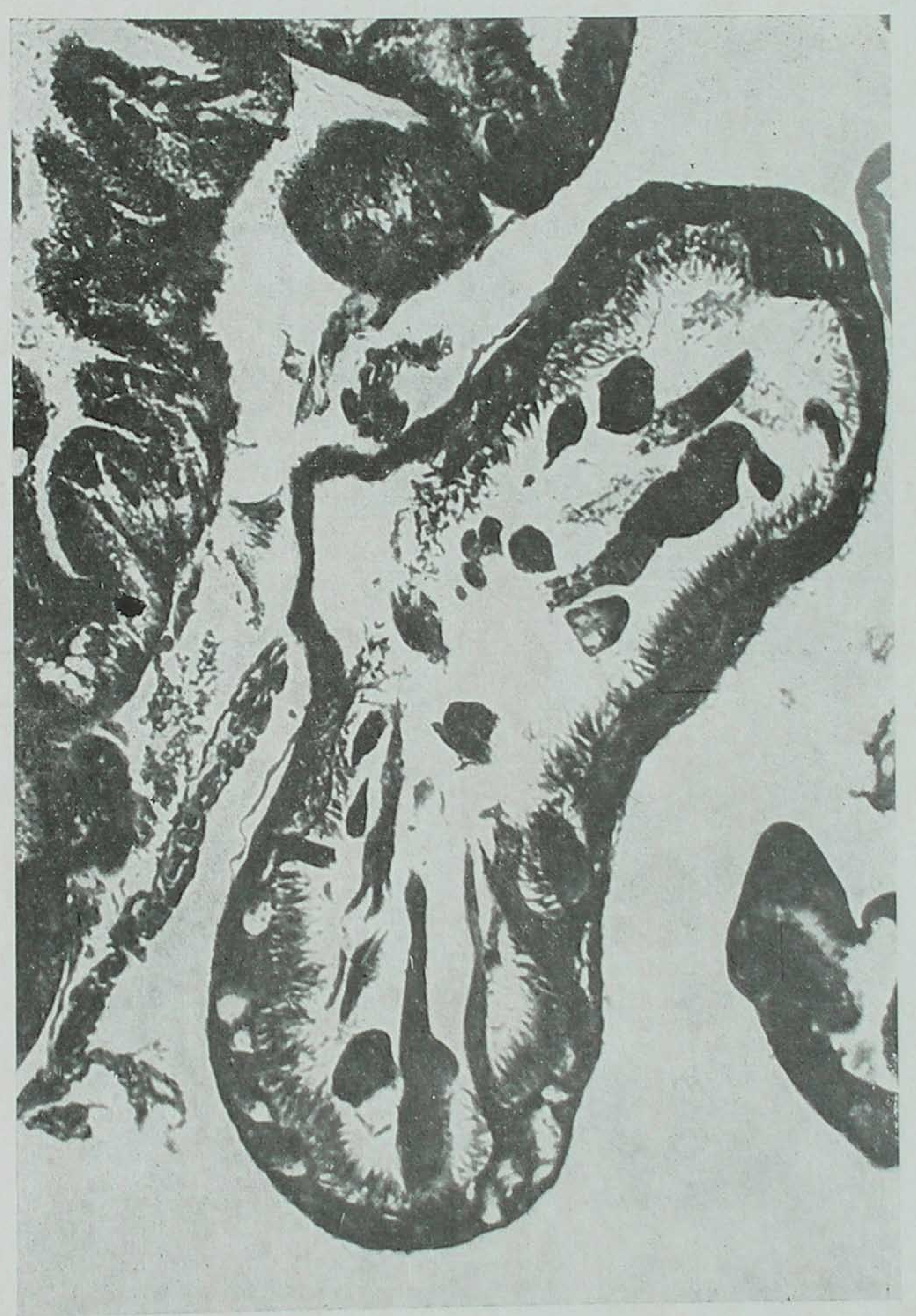




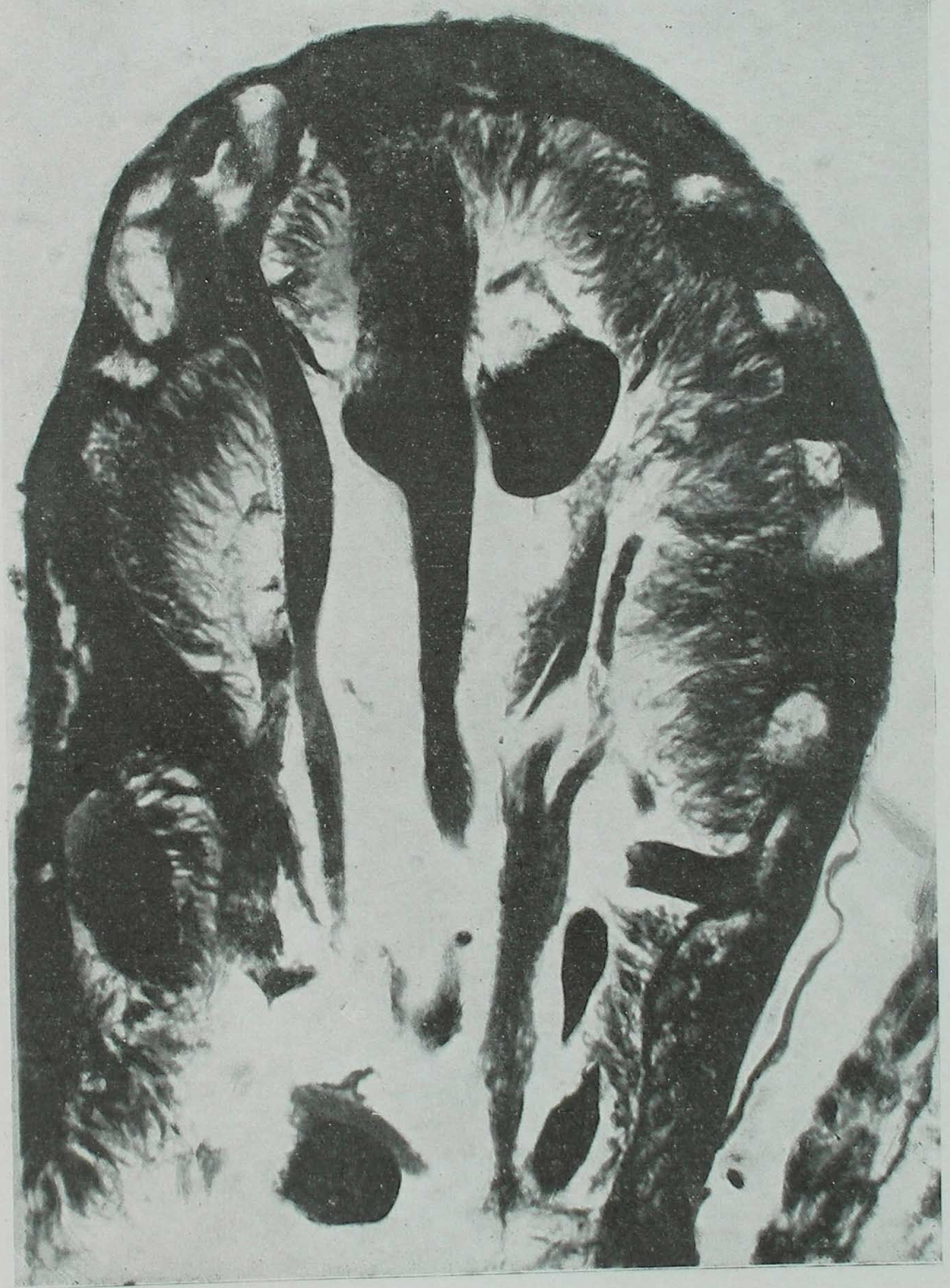

Emmanuel Dias: Formas de evolução do $T$. cruzi. 